\title{
The efficacy of early language intervention in mainstream school settings: a randomized controlled trial
}

\author{
Silke Fricke, ${ }^{1}$ (D) Kelly Burgoyne, ${ }^{2}$ Claudine Bowyer-Crane, ${ }^{3}$ Maria Kyriacou, ${ }^{2}$ Alexandra \\ Zosimidou, ${ }^{1}$ Liam Maxwell, ${ }^{1}$ Arne Lervàg, ${ }^{4}$ Margaret J. Snowling, ${ }^{5}$ and Charles Hulme ${ }^{6}$ \\ ${ }^{1}$ Department of Human Communication Sciences, University of Sheffield, Sheffield; ${ }^{2}$ Division of Psychology and \\ Language Sciences, University College London, London; ${ }^{3}$ Department of Education, University of York, York, UK; \\ ${ }^{4}$ Department of Education, University of Oslo, Oslo, Norway; ${ }^{5}$ Department of Experimental Psychology, St John's \\ College, University of Oxford, Oxford; ${ }^{6}$ Department of Education, University of Oxford, Oxford, UK
}

\begin{abstract}
Background: Oral language skills are a critical foundation for literacy and more generally for educational success. The current study shows that oral language skills can be improved by providing suitable additional help to children with language difficulties in the early stages of formal education. Methods: We conducted a randomized controlled trial with 394 children in England, comparing a 30-week oral language intervention programme starting in nursery $(N=132)$ with a 20-week version of the same programme starting in Reception $(N=133)$. The intervention groups were compared to an untreated waiting control group $(N=129)$. The programmes were delivered by trained teaching assistants (TAs) working in the children's schools/nurseries. All testers were blind to group allocation. Results: Both the 20- and 30-week programmes produced improvements on primary outcome measures of oral language skill compared to the untreated control group. Effect sizes were small to moderate $(20$-week programme: $d=.21 ; 30$-week programme: $d=.30$ ) immediately following the intervention and were maintained at follow-up 6 months later. The difference in improvement between the 20-week and 30-week programmes was not statistically significant. Neither programme produced statistically significant improvements in children's early word reading or reading comprehension skills (secondary outcome measures). Conclusions: This study provides further evidence that oral language interventions can be delivered successfully by trained TAs to children with oral language difficulties in nursery and Reception classes. The methods evaluated have potentially important policy implications for early education. Keywords: Early intervention; language; reading; RCT design; education.
\end{abstract}

\section{Introduction}

It is generally assumed that children enter school with sufficiently well-developed oral language skills to benefit from education. Indeed, language is the medium of instruction in all mainstream schools and, importantly, it is also the foundation of literacy skills (Hulme, Nash, Gooch, Lervåg, \& Snowling, 2015; NICHD Early Child Care Research Network, 2005). It follows that children who enter school with poor language skills are at high risk of educational underachievement (Conti-Ramsden, Durkin, Simkin, \& Knox, 2009; Roulstone, Law, Rush, Clegg, \& Peters, 2011; Snowling, Adams, Bishop, \& Stothard, 2001). There is particularly strong evidence that a wide range of nonphonological language skills, including vocabulary knowledge and grammatical skills are critically important for the development of reading comprehension (Clarke, Snowling, Truelove, \& Hulme, 2010; Fricke, Bowyer-Crane, Haley, Hulme, \& Snowling, 2013). We target those skills in the intervention reported here.

Interventions to improve the language skills of children with difficulties in this area are potentially of great educational importance. Studies have typically involved vocabulary training and shared book

Conflict of interest statement: No conflicts declared. reading activities. In general, vocabulary interventions produce improvements on measures of directly taught words with moderate effect sizes but generalization is poor. For example, Neuman, Newman, and Dwyer (2011) reported that 12-15 min of vocabulary training each day for 'at-risk' preschoolers had negligible effects on a standardized vocabulary measure. More generally, Elleman, Lindo, Morphy, and Compton (2009), in a meta-analysis of vocabulary interventions for children from preschool to grade 12 both with and without learning difficulties, found small effect sizes for vocabulary measures $(d=.29$, $k=14$ ), but a large effect size for directly taught skills $(d=.79, k=18)$.

The practice of shared book reading, in which a child and adult 'read' a book together jointly and discuss its contents, appears to be a more promising strategy for boosting language skills. Lonigan, Shanahan, and Cunningham (2008) reported a large effect of shared book reading on measures of oral language $(d=.73, k=16)$ whether implemented by parents or in school settings. Moderate to large effects were also found in a meta-analysis by Mol, Bus, de Jong, and Smeets (2008).

A similar picture emerges from studies which have investigated the efficacy of speech and language therapy for children's language disorders. A review by Law, Garrett, and Nye (2004), excluding interventions of 
less than 8 weeks duration, found no overall effect of language interventions on expressive language skills although there were significant effects for both syntax and vocabulary when children with receptive language impairments were excluded. None of the therapies improved receptive language abilities. Similar negative conclusions come from reviews by Boyle, McCartney, O'Hare, and Law (2010), and Cirrin and Gillam (2008), although a review of 'what works' integrating data from treatment studies with views of parents suggests there are a growing number of language interventions for which there is 'indicative' evidence (Law, Roulstone, \& Lindsay, 2015). There is therefore an urgent need for studies evaluating suitable interventions for use in the early years (before age 6) using rigorous methodologies.

One approach that has been found to be effective in mainstream schools is an oral language intervention promoting vocabulary, narrative and listening skills, delivered by trained teaching assistants (TAs; Bowyer-Crane et al., 2008). Children receiving this intervention shortly after school entry made more progress in vocabulary and grammar than children receiving an alternative treatment focusing on phonology and early reading skills (see also Bianco et al., 2010). An extension of this approach, starting the intervention before school entry and supplementing it with training in prereading skills for the final 10 weeks, reported robust effects on oral language and narrative skills, phoneme awareness and letter knowledge ( $d s=.30-.83$; Fricke et al., 2013). Children receiving intervention also showed significant gains in reading comprehension 1 year after the intervention finished.

Here, we report a replication and extension of the study by Fricke et al. (2013) in which the UK-based children's communication charity I CAN was licensed to distribute the programme, and trained and supported TAs in its delivery. We had the following hypotheses:

1. The intervention would lead to gains in oral language skills for children with poor language.

2. We anticipated that the size of the intervention effects would be reduced compared to the original trial, given that there is typically a reduction in effect size over successive trials (Ioannidis, 2006). This is likely to be particularly the case when the research team is not involved in training.

3. A subsidiary aim was to compare the extent to which a 30-week programme, beginning in the last term of nursery and continuing for 20 weeks in Reception class, was more effective than simply delivering a 20-week programme starting in Reception class. We predicted that the 30-week programme would produce larger gains although we had no confident predictions about the size of such an effect.

4. Since oral language interventions have been found to promote reading comprehension (Clarke et al., 2010; Fricke et al., 2013), we predicted that the intervention group would show improved reading comprehension.

\section{Methods}

A randomized controlled trial (RCT) was conducted where children from 34 nurseries were allocated to a 30-week intervention, a 20-week intervention or a waiting control group. Children in the 30-week intervention group received the Nuffield Early Language Intervention programme (following Fricke et al., 2013). This was delivered for 10 weeks in nursery (last term of preschool in England before entering formal schooling; ages 3-4) and continued for 20 weeks in Reception (first year of primary school in England; ages 4-5). The 20week intervention group received only the final 20 weeks of the intervention in their primary schools (Reception), while the waiting control group received their usual school provision. It should be noted that this design with children in different conditions nested within schools means that there is the possibility of contamination effects. In practice such effects seem unlikely to have occurred since nurseries/schools were aware of the importance of adhering to the study design. To the extent to which such leakage does occur it can only serve to reduce the estimates of the effectiveness of the interventions.

From the beginning of Year 1 (term following post-testing), schools were given permission to deliver additional language and literacy support to the waiting control group. Fifteen schools opted for TA training to enable delivery of a targeted language and literacy intervention provided by the research team to the waiting control group. The programme offered was different to the Nuffield Early Language Intervention (which would not have been age-appropriate). However, by delayed follow-up testing only eight of these schools had started to implement it. The remaining 19 schools chose to include children in the waiting control group in the school's existing language and reading support programmes.

The study was granted ethical approval by UCL's Research Ethics Committee. Schools were recruited and trained to deliver the intervention programme by I CAN. Head teachers gave consent for the intervention to be delivered in their schools, and for screening assessments. Informed parental consent was obtained for all project phases following screening.

Children were assessed before the start of intervention at screening $(t 0)$ and pretest $(t 1)$, immediately following intervention (post-test, $t 2$ ) and at delayed follow-up ( $t 3$, roughly 6 months after $t 2$ ). All testers were blind to group allocation. While the waiting control group remained untreated until posttest, by the time of the delayed follow-up some of these children had started to receive school-based language and literacy support, although the specific nature, quality and intensity of this varied widely. The timeline for assessments and intervention delivery is presented in Figure 1.

\section{Participants}

In accordance with the CONSORT guidelines (Schulz, Altman, $\&$ Moher, 2010) Figure 2 shows details of the recruitment, allocation and flow of participants through the study (see Appendix S2 for the CONSORT checklist). Sample size was determined based on budget constraints, and a formal power calculation that showed that with $N=120$ per arm there was better than $80 \%$ power to detect a difference between groups equivalent to $d=.29$ ( $p<.05$, two-tailed).

Our intervention (Fricke et al., 2013) is designed to improve the oral language skills of children with language difficulties in mainstream nurseries and Reception classes. We, therefore, used an equivalent recruitment procedure to that in our previous study. Three hundred and two primary schools with attached nurseries in generally disadvantaged areas and with mainly monolingual English-speaking pupils on their registers 


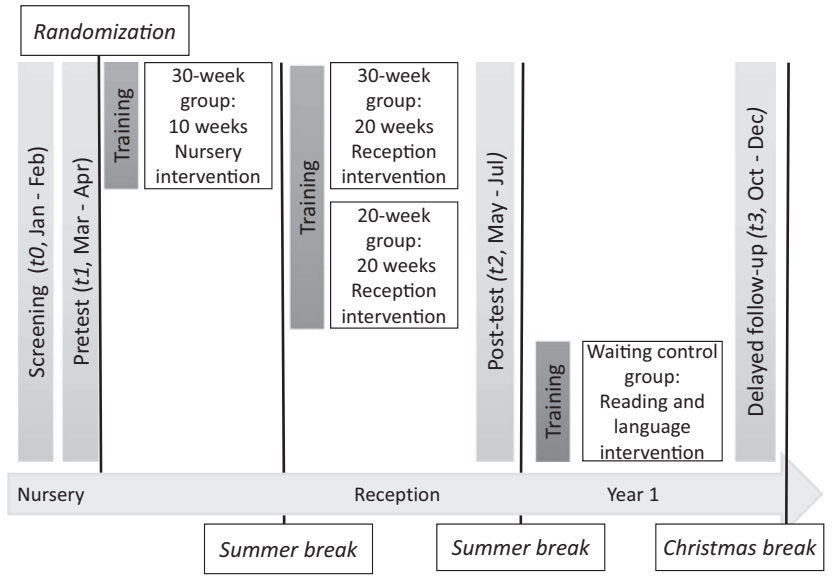

Figure 1 Timeline of project showing assessment, training and intervention phases

were approached by I CAN with information about the study. Of these, 34 schools (Greater London: 17; Yorkshire/Nottinghamshire: 17) agreed to take part. All children in these nurseries who were due to enter school (Reception in England) the following academic year were screened. Children who were on a school's special educational needs register for difficulties other than language, and children learning English as an Additional Language who had not yet acquired sufficient English language skills to participate in the assessments, were not included in the screening.

Within each school/nursery, 15 children with the lowest mean verbal composite score based on scaled scores on the screening measures [Clinical Evaluation of Language Fundamentals (CELF) Preschool II UK Sentence Structure and Expressive Vocabulary subtests; Semel, Wiig, \& Secord, 2006] were selected as possible participants in the study. To validate this initial selection, individual assessments using further language and early literacy measures were conducted $(t 1$; see below). Up to 12 children in each nursery $(N=394$; $M_{\text {age }}=3 ; 11$ ) were selected to take part in the RCT based on the following criteria; (a) having the lowest mean verbal composite scores in their school/nursery (derived from $z$-scores on screening measures and the British Picture Vocabulary Scale (BPVS; Dunn, Dunn, \& Styles, 2009) and (b) entering Reception at the same primary school they attended for nursery. Within each school/nursery children were allocated to either the 30-week intervention $(N=132)$, the 20-week intervention $(N=133)$ or waiting control groups $(N=129)$. Group allocation was conducted independently by the Institute for Fiscal Studies and involved minimization (Altman \& Bland, 2005) for gender, age and the verbal composite score.

We assessed the number of children in the sample who could be considered to have clinically significant language difficulties by using standard scores from three standardized tests administered at screening and pretest (BPVS, CELF Expressive Vocabulary, CELF Sentence Structure). The mean standard scores for the sample as a whole on these tests were: BPVS $=86.21$ (range 69-118), CELF Expressive Vocabulary $=86.95$ (range 50-145), CELF Sentence Structure $=78.35$ (range 60-120). Thus, the sample recruited has standardized language scores in the low-average range. However, some 186/ $394(47 \%)$ children were at the 14 th centile or below on the three tests and $149 / 394(38 \%)$ were at or below the 10 th centile on all three tests. Thus, a high proportion of the sample had clinically significant language difficulties.

\section{Assessment measures}

Primary outcome measures were standardized and nonstandardized tests of language ability. Early literacy skills (letter- sound knowledge and word reading) and reading comprehension were secondary outcome measures. The same measures as those used in Fricke et al. (2013) were employed where possible to allow direct comparisons. Some additional measures such as statutory data collected by schools are not reported here.

\section{Screening (t0), pre- $(t 1)$, post- (t2), and delayed follow-up ( $t 3)$ tests}

Language skills. Vocabulary: Expressive vocabulary knowledge was measured using the CELF Expressive Vocabulary subtest $(t 0, t 2, t 3)$ and the Information Score from the Renfrew Action Picture Test (APT; Renfrew, 2003; t1-t3). Receptive vocabulary skills were assessed using the BPVS $(t 1-t 3)$.

Grammar: Grammatical skills were measured using the CELF Sentence Structure subtest $(t 0, t 2, t 3)$ and the APT Grammar Score (t1-t3).

Listening comprehension: Children's listening comprehension skills were tested by asking children to listen to two short stories adapted from the York Assessment of Reading for Comprehension (YARC, Snowling et al., 2009) and answer questions about them ( $t 1-t 3)$.

Taught vocabulary: A random selection of the vocabulary taught in the nursery and Reception parts of the intervention was assessed using Picture Naming ( $t 1-t 3)$ and by asking children to provide a definition of words (Definitions; $t 1-$ t3).

Early literacy skills. Letter-sound knowledge: The Letter-Sound Knowledge subtest from the YARC (core version $t 1$, extended version $t 2-t 3$; Hulme et al., 2009) was used.

Word-level reading: Word level reading accuracy was measured using the YARC Early Word Reading subtest ( $t 1-t 3$; Hulme et al., 2009).

Reading comprehension: The two beginner passages from the YARC Passage Reading test (Snowling et al., 2009) were used to assess children's reading comprehension ( $t 3)$.

\section{Training and intervention programme}

Children allocated to the intervention groups received the Nuffield Early Language Intervention which aims to improve children's vocabulary, develop narrative skills, encourage active listening, and build confidence in independent speaking. Children allocated to the 30-week intervention group received the intervention in nursery (10 weeks) and continued in Reception (20 weeks) as described by Fricke et al. (2013). Children allocated to the 20-week intervention group only received the Reception part of the programme.

During the first 10 weeks in nursery, three 20-min sessions were delivered each week to groups of two to four children (total small group intervention time: $10 \mathrm{hr}$ ). Topic areas covered as part of the vocabulary work are 'Family \& Friends' (15 sessions) and 'Our House' (15 sessions). The 20 weeks in Reception consist of fifty-seven 30-min small group sessions (2-4 children) and thirty-seven 15-min individual sessions with children participating in three group and two individual sessions per week (total intervention time: small group $28.5 \mathrm{hr}$; one-to-one $9.25 \mathrm{hr}$ ). In the last 10 weeks the active 


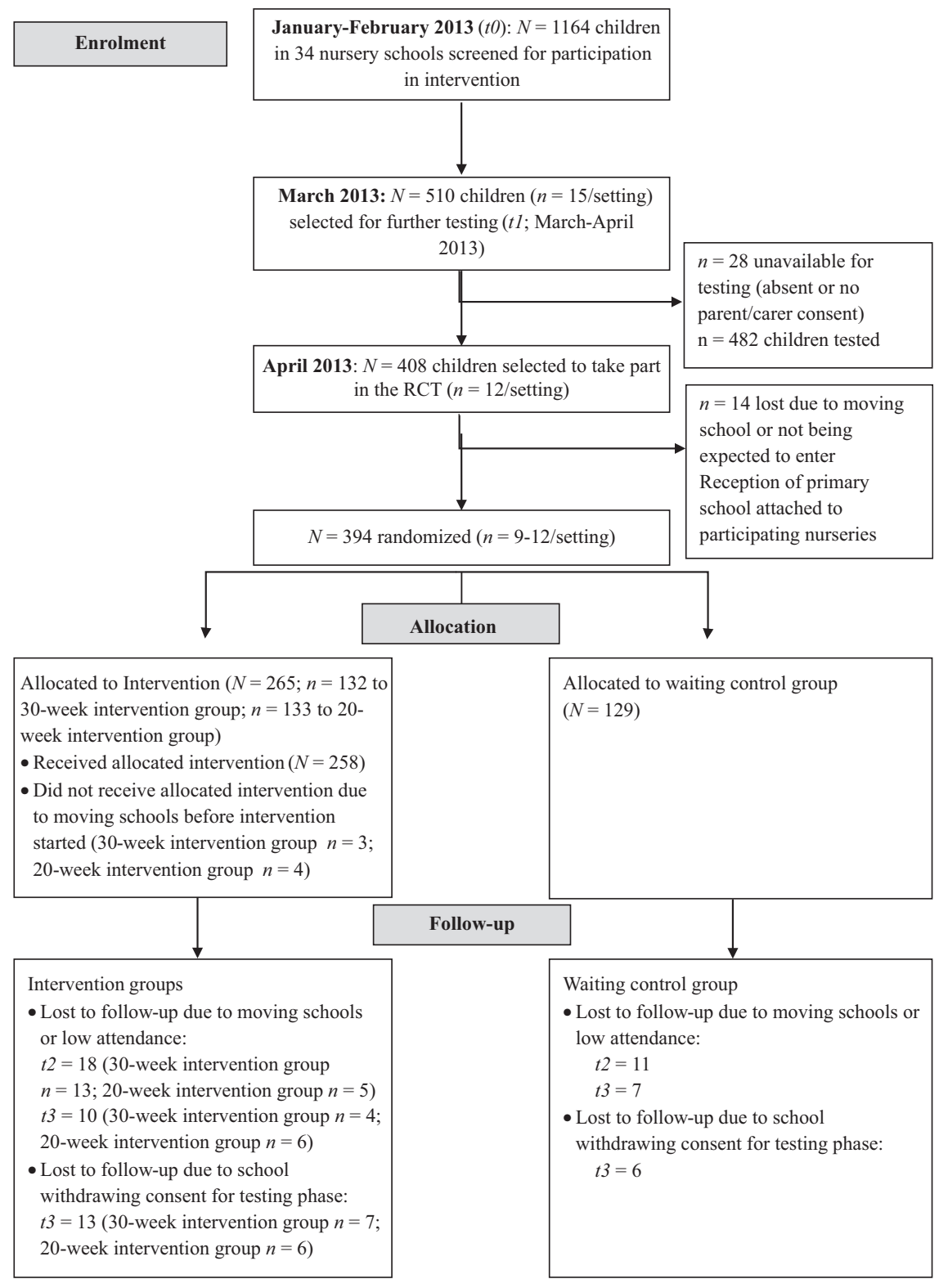

Figure 2 CONSORT diagram showing flow of participants through randomized controlled trial (RCT) study

listening work is extended to incorporate explicit activities to promote phonological awareness and letter-sound knowledge; these programme elements were designed to reinforce the literacy instruction all children receive in school. Whenever possible, phonological awareness and letter-sound knowledge activities incorporated taught vocabulary in order to further consolidate these words. The topic areas covered in Reception are 'My Body', 'Things we wear', 'People who help us', 'Growing', 'Journey' and 'Time'. The listening work in the first 20 weeks targets children's active listening skills and incorporates auditory discrimination, memory, and sequencing as well as rhyming activities in line with phase 1 of the phonics resource Letters and Sounds (DfES, 2007). In the last 10 weeks, the listening activities are extended to include activities targeting phonological awareness (blending and segmenting) and letter-sound knowledge.

The Nuffield Early Language Intervention teaches children using multisensory techniques within a standard framework (see Appendix S1 for details). The programme was designed with reference to the Primary Framework for Literacy and Mathematics (DfES, 2006), the Statutory Framework for the Early Years Foundation Stage (DCSF, 2008) and in consultation with teachers and speech and language therapists. Topics and vocabulary were selected to cover different word types and vocabulary is taught using a multicontextual approach within a repetitive framework that follows established principles for teaching listening, vocabulary and narrative (Beck \& McKeown, 2007; Beck, McKeown, \& Kucan, 2013; Carroll, Bowyer-Crane, Duff, Hulme, \& Snowling, 2011; Locke, 2006). Narrative work allows the use of taught vocabulary in connected speech and introduces children to key story elements and sequencing of events while encouraging expressive language and grammatical competence.

The intervention was delivered by TAs selected by their nursery/school who were trained and supported by I CAN. The training content was based on that used in Fricke et al. (2013). TAs received 1 day of training prior to delivering the nursery part and two further training days prior to the Reception part. I CAN also offered telephone support on request to TAs. The training for this field trial differed from the research trial in two ways: in contrast to Fricke et al. (2013), TAs did not receive a 1-day refresher training before the last 10-week block in Reception, and the level of support they received during the intervention phase was much reduced. The role of the research team in delivering the intervention was limited to monitoring treatment fidelity and attendance through observations of teaching in 
nursery (one group session) and Reception (two group and two individual sessions), and collecting completed record forms from TAs. Following the observations, feedback was provided and areas of improvement discussed as necessary.

\section{Results}

Teaching assistants delivered on average 28.44/30 $(S D=4.35$, range: $10-30)$ group sessions to the 30 week intervention group in nursery and 49.17/57 $(S D=13.22$, range $10-58)$ group sessions in Reception. For the 20-week intervention group TAs delivered on average 48.72/57 $(S D=13.55$, range: 10-57) group sessions in Reception. The number of sessions each child attended varied considerably (30 weeks: Nursery group sessions: $M=24.69$, $S D=6.37$, range: $0-30$; Reception group sessions: $M=38.51, S D=20.62$, range: 0-57; Individual sessions: $\quad M=21.91, \quad S D=15.37$, range: $0-43$; 20 weeks: Reception group sessions $M=41.11$, $S D=19.65$, range: $0-57$; Individual sessions: $M=23.01, S D=15.40$, range: $0-44)$. Although the range of sessions completed varied widely, preliminary analyses showed no significant relationship between the number of sessions delivered and the degree of improvement on measures of language skills. Data from all children for whom t2 data are available are included in the analyses.

In addition to recording the number of sessions attended, some teaching sessions were observed to assess treatment fidelity. We graded the quality of teaching of different session components on a 5-point scale with the manual instructions as a reference point $(1=$ several aspects missing/not satisfactory, 2 = some aspects missing/not satisfactory, $3=$ according to manual, 4 = according to manual with good use of resources/questions/techniques to support language, 5 = according to manual with very good use of resources / questions / techniques). On average, TAs achieved a mean quality rating of $2.83(S D=0.46$, Range 2.00-3.83) for group sessions observations in nursery, $2.95(S D=0.49$, Range $1.80-4.00)$ in the first 10 weeks in Reception, and 3.20 ( $S D=0.58$, Range 2.00-4.43) in the second 10 weeks in Reception. Fidelity and quality ratings for individual sessions tended to be lower than for more manualized group sessions (first 10 weeks in Reception: $M=2.74, \quad S D=0.55, \quad$ Range $1.20-3.80 ;$ second 10 weeks: $M=2.83, S D=0.56$, Range 1.83-4.00).

Descriptive statistics for all outcome measures at screening, pretest, post-test and delayed follow-up for the 30-week intervention, 20-week intervention and waiting control groups are shown in Table 1 . It is clear that the groups are approximately equated on all measures at screening/pretest (all ps $>$.273), as expected given allocation with minimization for age, gender and verbal composite scores. It is also clear that both the 20-week and 30-week interventions are associated with improvements on the majority of language measures although effect sizes differ between measures (30-week intervention: $d \mathrm{~s}=.01-.46 ; 20$-week intervention: $d \mathrm{~s}=.08-.23$ )

All analyses were performed on an intention-totreat basis. The majority of the analyses were conducted in Stata 14.0 (Stata Corp, College Station, TX). Structural equation models (SEM) were constructed using Mplus 7.4 (Muthén \& Muthén, 19982015) with Full Information Maximum Likelihood estimators to allow for missing data and robust (Huber-White) standard errors to allow for the clustering of children within schools. Little's MCAR test confirmed that missing data for the language and literacy measures used in the SEM models could be considered to be missing completely at random $\left(\chi^{2}=22.12 ; d f=17 ; p=.181\right)$.

\section{Effects of intervention on directly taught skills}

Table 2 shows descriptive statistics for each group on taught vocabulary measures and a summary of the effects of intervention. There were effects for both intervention groups on taught vocabulary measures compared to the waiting control group which tended to be larger at post-test $(d s=.19-1.07)$ than at delayed follow-up ( $d s=.08-.66)$. In contrast, differences between the 30-week and 20-week intervention groups were very small (post-test: $d \mathrm{~s}=.04-.15$; delayed follow-up: $d s=.03-.22)$. Differences between groups on directly taught vocabulary measures were assessed in hierarchical linear (ANCOVA) models with initial level of performance on the same measure as covariate, and with varying intercepts and fixed slopes across schools. These models account for the nonindependence of observations due to children being clustered within schools. To test the assumption of homogeneity of regression slopes across groups the group $\times$ covariate interaction terms were included in initial models but were dropped from the models reported since these effects were not significant and of negligible magnitude. The absence of group by covariate interactions justifies the use of the simpler models with parallel slopes.

\section{Effects on primary outcomes (standardized and nonstandardized measures of oral language)}

Our principal interest was to examine the extent to which the interventions produced improvements on a broad language factor defined by our primary outcome measures (i.e. standardized and nonstandardized tests of language ability: CELF Expressive Vocabulary, CELF Sentence Structure, BPVS, Listening Comprehension, APT Information and Grammar scores). Such a measure assesses an underlying language factor that captures the common variance shared by the different language measures. The model used is shown in Figure 3 and provides an excellent fit to the data $\left[\chi^{2}(145)=178.582, p=.030\right.$; RMSEA $=.024$ [90\% CI 0.008-0.035]; CFI =.890; TFI $=.986)$. In this model, variance in the pretest, 
Table 1 Mean raw scores $(S D)$ for 30-week intervention, 20-week intervention and waiting control groups for primary and secondary outcome measures at screening $(t 0)$, preintervention $(t 1)$, immediately postintervention $(t 2)$ and delayed follow-up $(t 3$; with effect sizes for intervention effects)

\begin{tabular}{|c|c|c|c|c|c|c|c|c|c|c|}
\hline & \multirow[b]{2}{*}{ Reliability } & \multicolumn{2}{|c|}{$\begin{array}{c}30 \text {-week } \\
\text { intervention } \\
n=132\end{array}$} & \multicolumn{2}{|c|}{$\begin{array}{c}20 \text {-week } \\
\text { intervention } \\
n=133\end{array}$} & \multicolumn{2}{|c|}{$\begin{array}{l}\text { Waiting } \\
\text { control } \\
n=129\end{array}$} & \multicolumn{3}{|c|}{ Cohen's $d$} \\
\hline & & $M$ & $S D$ & $M$ & $S D$ & $M$ & $S D$ & $30 \leftrightarrow 20$ & $30 \leftrightarrow \mathrm{WC}$ & $20 \leftrightarrow \mathrm{WC}$ \\
\hline \multicolumn{11}{|l|}{ Age (months) } \\
\hline to & & 46.01 & 3.40 & 46.08 & 3.57 & 46.16 & 3.59 & & & \\
\hline$t 2$ & & 61.54 & 3.27 & 61.57 & 3.60 & 61.75 & 3.69 & & & \\
\hline t3 & & 67.66 & 3.20 & 67.77 & 3.61 & 67.75 & 3.74 & & & \\
\hline \multicolumn{11}{|l|}{ Primary outcomes } \\
\hline CELF-EV & $.82^{\mathrm{a}}$ & & & & & & & & & \\
\hline t0-(40) & & 10.86 & 5.10 & 10.74 & 5.59 & 10.80 & 5.34 & & & \\
\hline$t 2-(40)$ & & 21.00 & 5.74 & 20.77 & 5.90 & 19.60 & 5.98 & $.02^{1}$ & $.26^{1}$ & $.23^{1}$ \\
\hline t3-(40) & & 24.71 & 6.14 & 24.29 & 5.91 & 22.90 & 6.56 & $.06^{1}$ & $.34^{1}$ & $.27^{1}$ \\
\hline CELF-SS & $.78^{\mathrm{a}}$ & & & & & & & & & \\
\hline t0-(22) & & 6.78 & 3.71 & 6.48 & 3.81 & 6.58 & 3.80 & & & \\
\hline$t 2-(22)$ & & 13.48 & 3.28 & 13.73 & 2.92 & 13.23 & 2.94 & $-.15^{1}$ & $.01^{1}$ & $.16^{1}$ \\
\hline$t 3-(22)$ & & 16.23 & 2.78 & 16.14 & 2.68 & 15.97 & 2.91 & $-.06^{1}$ & $.02^{1}$ & $.07^{1}$ \\
\hline BPVS & $.91^{\mathrm{a}}$ & & & & & & & & & \\
\hline$t 1-(168)$ & & 36.67 & 13.04 & 37.79 & 14.25 & 36.52 & 15.08 & & & \\
\hline$t 2-(168)$ & & 64.54 & 13.09 & 64.29 & 12.77 & 61.79 & 14.32 & $.10^{1}$ & $.18^{1}$ & $.09^{1}$ \\
\hline t3-(168) & & 74.86 & 9.27 & 73.36 & 12.30 & 72.35 & 11.16 & $.19^{1}$ & $.17^{1}$ & $-.02^{1}$ \\
\hline APT information & $.83^{\mathrm{b}}$ & & & & & & & & & \\
\hline$t 1-(40)$ & & 20.70 & 6.38 & 20.02 & 6.08 & 20.44 & 6.00 & & & \\
\hline$t 2-(40)$ & & 28.08 & 4.66 & 28.24 & 4.58 & 27.60 & 4.74 & $-.14^{1}$ & $.04^{1}$ & $.18^{1}$ \\
\hline$t 3-(40)$ & & 29.93 & 4.23 & 29.85 & 4.15 & 29.15 & 4.52 & $-.10^{1}$ & $.08^{1}$ & $.19^{1}$ \\
\hline APT grammar & $.89^{\mathrm{b}}$ & & & & & & & & & \\
\hline$t 1-(38)$ & & 14.33 & 6.31 & 13.53 & 5.96 & 13.89 & 5.59 & & & \\
\hline$t 2-(38)$ & & 22.70 & 4.72 & 22.05 & 5.23 & 21.31 & 4.99 & $-.03^{1}$ & $.16^{1}$ & $.19^{1}$ \\
\hline t3-(38) & & 25.83 & 3.87 & 24.92 & 4.55 & 24.00 & 4.79 & $.02^{1}$ & $.23^{1}$ & $.22^{1}$ \\
\hline Listening comprehension & $.99^{\mathrm{b}}$ & & & & & & & & & \\
\hline$t 1-(16)$ & & 1.19 & 1.51 & 1.44 & 1.79 & 1.39 & 1.43 & & & \\
\hline$t 2-(16)$ & & 5.02 & 2.55 & 4.86 & 2.87 & 4.55 & 2.51 & $.25^{1}$ & $.46^{1}$ & $.15^{1}$ \\
\hline t3-(16) & & 6.62 & 2.96 & 6.42 & 3.07 & 6.25 & 2.47 & $.27^{1}$ & $.39^{1}$ & $.07^{1}$ \\
\hline \multicolumn{11}{|l|}{ Secondary outcomes } \\
\hline YARC-Letter Knowledge & $.95^{\mathrm{a}}$ & & & & & & & & & \\
\hline$t 1-(17)$ & & 1.60 & 2.71 & 2.14 & 2.96 & 1.79 & 2.58 & & & \\
\hline$t 2-(32)$ & & 27.12 & 3.86 & 26.87 & 5.66 & 26.57 & 5.49 & $.26^{1}$ & $.28^{1}$ & $.00^{1}$ \\
\hline t3-(32) & & 29.65 & 2.55 & 29.41 & 3.47 & 29.12 & 3.90 & $.27^{1}$ & $.27^{1}$ & $-.02^{1}$ \\
\hline YARC-Early Word Reading & $.98^{\mathrm{a}}$ & & & & & & & & & \\
\hline$t 1-(30)$ & & 0.34 & 2.10 & 0.12 & 0.86 & 0.09 & 0.80 & & & \\
\hline$t 2-(30)$ & & 8.90 & 5.99 & 9.94 & 7.14 & 8.87 & 6.74 & $-.17^{2}$ & $.00^{2}$ & $.17^{2}$ \\
\hline$t 3-(30)$ & & 16.20 & 7.98 & 16.27 & 8.53 & 14.72 & 7.63 & $-.01^{2}$ & $.19^{2}$ & $.19^{2}$ \\
\hline YARC-Reading comprehension & $.77^{\mathrm{a}}$ & & & & & & & & & \\
\hline$t 3-(16)$ & & 6.34 & 3.42 & 6.84 & 3.44 & 6.28 & 2.94 & $-.15^{2}$ & $.02^{2}$ & $.18^{2}$ \\
\hline
\end{tabular}

(), Maximum raw scores; CELF, Clinical Evaluation of Language Fundamentals; EV, Expressive Vocabulary; SS, Sentence Structure; BPVS, British Picture Vocabulary Scale; APT, Action Picture Test; YARC, York Assessment of Reading for Comprehension.

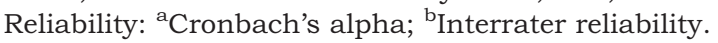

Cohen's $d$ : 1 = difference in progress between groups divided by pooled initial $S D ; 2=$ difference in means at post-test/follow-up divided by pooled $S D$ at post-test/follow-up (pretest scores were at floor/not available so could not be used).

post-test and delayed follow-up language scores is captured by six latent variables (Language Pretest, Language Post-test, Language Delayed Follow-up, APT Pretest, APT Post-test, APT Delayed Follow-up). The language pretest, post-test and delayed followup factors reflect shared variance across all language measures at each time point, while the APT factors account for variance that is shared by APT Information and Grammar scores but which is not shared with the other language measures. The APT factors were included in the model to improve fit since the APT measures shared significant variance with each other which was not accounted for by the language latent variable (it is likely that the APT factor reflects shared measurement variance since both scores come from the same test).

It is notable that the language factors show considerable longitudinal stability and the APT factors moderate stability. In this model, the unstandardized regression weights from the language pretest to the two language post-test factors are fixed to be equal [a Wald Test shows that this constraint results in no loss of fit in comparison to a model in which the paths were freely estimated; $\left.\chi^{2}(1)=2.991, p=.084\right]$. 
Table 2 Mean raw scores $(S D)$ and intervention effects for 30-week intervention, 20-week intervention and waiting control groups preintervention $(t 1)$, immediately postintervention $(t 2)$ and at delayed follow-up $(t 3)$ for directly taught vocabulary measures

\begin{tabular}{|c|c|c|c|c|c|c|c|c|c|c|c|c|c|}
\hline & \multicolumn{2}{|c|}{$\begin{array}{c}\text { 30-week } \\
\text { intervention }\end{array}$} & \multicolumn{2}{|c|}{$\begin{array}{c}20 \text {-week } \\
\text { intervention }\end{array}$} & \multicolumn{2}{|c|}{$\begin{array}{l}\text { Waiting } \\
\text { control }\end{array}$} & \multicolumn{3}{|c|}{ Cohen's $d$} & \multicolumn{4}{|c|}{ Hierarchical linear model } \\
\hline & \multirow[b]{2}{*}{$M$} & \multirow[b]{2}{*}{$S D$} & \multirow[b]{2}{*}{$M$} & \multirow[b]{2}{*}{$S D$} & \multirow[b]{2}{*}{$M$} & \multirow[b]{2}{*}{$S D$} & \multirow[b]{2}{*}{$30 \leftrightarrow 20$} & \multirow[b]{2}{*}{$30 \leftrightarrow \mathrm{WC}$} & \multirow[b]{2}{*}{$20 \leftrightarrow \mathrm{WC}$} & \multicolumn{2}{|c|}{$30 \leftrightarrow \mathrm{WC}$} & \multicolumn{2}{|c|}{$20 \leftrightarrow \mathrm{WC}$} \\
\hline & & & & & & & & & & $z$ & $p$ & $z$ & $p$ \\
\hline \multicolumn{14}{|c|}{ Nursery-expressive naming } \\
\hline$t 1-(14)$ & 5.43 & 2.44 & 5.50 & 2.40 & 5.49 & 2.35 & & & & & & & \\
\hline$t 2-(14)$ & 9.43 & 1.77 & 9.14 & 1.92 & 8.67 & 1.73 & 0.15 & 0.34 & 0.19 & 3.81 & $<.001$ & 2.22 & .027 \\
\hline t3-(14) & 10.59 & 1.58 & 10.12 & 1.84 & 9.91 & 1.64 & 0.22 & 0.31 & 0.08 & 3.30 & .001 & 1.06 & .289 \\
\hline \multicolumn{14}{|c|}{ Nursery definitions } \\
\hline$t 1-(48)$ & 4.24 & 3.57 & 4.35 & 3.63 & 4.48 & 3.28 & & & & & & & \\
\hline$t 2-(48)$ & 13.97 & 6.45 & 13.67 & 6.44 & 11.56 & 5.60 & 0.09 & 0.84 & 0.73 & 3.55 & $<.001$ & 2.89 & .004 \\
\hline$t 3-(48)$ & 15.63 & 5.91 & 15.62 & 6.12 & 14.24 & 6.39 & 0.03 & 0.54 & 0.50 & 2.30 & .022 & 2.02 & .043 \\
\hline \multicolumn{14}{|c|}{ Reception-expressive naming } \\
\hline$t 1-(24)$ & 7.71 & 3.08 & 7.75 & 3.18 & 7.80 & 3.27 & & & & & & & \\
\hline$t 2-(24)$ & 14.83 & 3.08 & 14.74 & 3.37 & 11.52 & 2.84 & 0.03 & 1.07 & 1.03 & 10.24 & $<.001$ & 9.80 & $<.001$ \\
\hline$t 3-(24)$ & 15.52 & 2.76 & 15.46 & 2.82 & 13.52 & 3.02 & 0.03 & 0.66 & 0.62 & 6.35 & $<.001$ & 5.93 & $<.001$ \\
\hline \multicolumn{14}{|c|}{ Reception definitions } \\
\hline$t 1-(54)$ & 4.03 & 3.46 & 4.17 & 3.59 & 4.12 & 3.74 & & & & & & & \\
\hline$t 2-(54)$ & 13.43 & 6.50 & 13.35 & 6.80 & 11.68 & 5.86 & 0.06 & 0.51 & 0.44 & 2.67 & .008 & 2.05 & .040 \\
\hline t3-(54) & 16.00 & 5.20 & 15.55 & 5.91 & 14.38 & 5.56 & 0.17 & 0.47 & 0.31 & 2.78 & .005 & 1.75 & .080 \\
\hline
\end{tabular}

(), Maximum raw scores; Cohen's $d$ : difference in progress between groups divided by pooled initial $S D$.

Also, each pair of unstandardized regression weights from each of the dummy codes $(20$-week intervention $\rightarrow$ Language Post-test; 20-week intervention $\rightarrow$ Language Delayed Follow-up and 30-week intervention $\rightarrow$ Language Post-test; 30-week intervention $\rightarrow$ Language Delayed Follow-up) were fixed to be equal. These constraints provide a direct test of whether each of the intervention effects differ in size between the immediate and delayed post-tests. Once again imposing these constraints resulted in negligible changes in model fit [Wald Test: $\chi^{2}(2)=0.628$, $p=.730$ ] confirming that the size of the intervention effects did not differ between the two testing times.

The most critical result from this analysis is that both the 20-week and 30-week intervention groups show a significantly greater increase in their scores on the language post-test and delayed follow-up factors (controlling for pretest scores) than the waiting control group $[d=.21 \quad(95 \%$ CI 0.044 $0.366)$ and $d=.30$ (95\% CI $0.130-0.468)$ respectively]. The extent of improvement does not differ between the two intervention groups [Wald test: $\chi^{2}(1)$ $=.842, p=.359$ ]. A critical assumption for this analysis is that there are equivalent slopes between language pretest and language post-test factor scores across groups. Analyses which included the interaction terms between pretest and group dummy codes confirmed that the slopes for the intervention groups did not differ significantly from the slope for the waiting control group at either post-test (20-week intervention: $\beta=.037, p=.236$; 30-week intervention: $\beta=.021, p=.520)$ or at delayed follow-up (20week intervention: $\beta=-.053, p=.258 ; 30$-week intervention: $\beta=-.071, p=.077$ ).

The clear absence of interactions between group and pretest scores in these analyses confirm that the slopes relating pretest to post-test language scores do not differ between groups. In other words, children with the most severe language difficulties at pretest respond to our intervention to the same degree as children with less severe difficulties. This pattern is illustrated in Figure 4.

It should also be noted that the model used here does not display factorial invariance (unstandardized loadings on the language factor differ across different testing times). This finding shows that the composition of the language factor varies over time (possibly partly because the different language tests show different degrees of improvement as a result of intervention). One implication of this is that we cannot make strong claims about the intervention having effects on a unitary underlying language factor. Nevertheless, the model gives an estimate of the size of change in language skills produced by our interventions when language is assessed by a latent variable with high reliability.

\section{Effects on secondary outcomes (early literacy and reading comprehension)}

We also examined whether the intervention had any effects on early literacy skills (i.e. letter-sound knowledge and word reading). Table 1 shows descriptive statistics for the effects of the intervention on these measures. We constructed a latent variable model for literacy, comparable to the one for language, which is shown in Figure 5. The model provides an excellent fit to the data $\left[\chi^{2}(15)=23.235, p=.079 ;\right.$ RMSEA $=.037$ (90\% CI 0.000-0.066); CFI $=.989$; TFI $=.980]$. In this model variance in pretest and post-test literacy scores is captured by three latent variables (Literacy Pretest, Literacy Post-test, Literacy Delayed Follow-up). The 


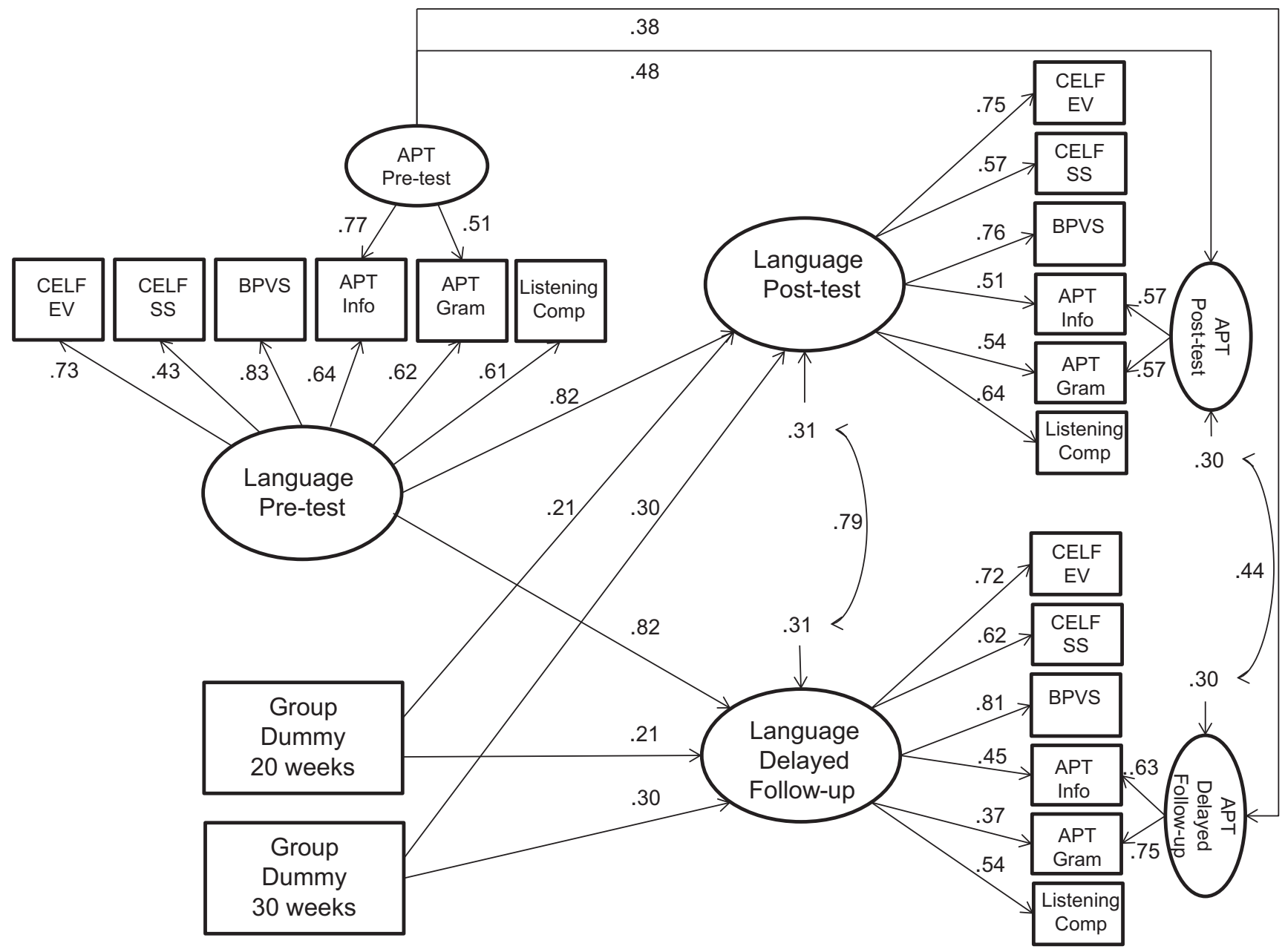

Figure 3 Model showing the effects of the interventions on language skills at immediate post-test and delayed follow-up. Standardized coefficients shown (except for dummy variables where y-standardized values are shown). Robust (Huber-White cluster estimators) standard errors are shown which do not differ appreciably from simple standard errors. A number of covariances between the same measures at adjacent time points were significant and included in the model, but not shown in the diagram. Note. CELF, Clinical Evaluation of Language Fundamentals; EV, Expressive Vocabulary; SS, Sentence Structure; BPVS, British Picture Vocabulary Scale; APT, Action Picture Test; Info, Information; Gram, Grammar; Comp, Comprehension

literacy factor shows moderate longitudinal stability which is consistent with the fact that this is a time of rapid changes in literacy skills, which were very low when first assessed in nursery.

In this model, the unstandardized regression weights from the literacy pretest to the two literacy post-tests were fixed to be equal as this did not result in a significant loss of fit [Wald Test: $\chi^{2}(1)=1.001$, $p=.317]$. Furthermore, each pair of unstandardized regression weights from each dummy code to the post-test and delayed follow-up factor were fixed to be equal (20-week intervention $\rightarrow$ Literacy Post-test; 20-week intervention $\rightarrow$ Literacy Delayed Follow-up, and 30-week intervention $\rightarrow$ Literacy Post-test; 30week intervention $\rightarrow$ Literacy Delayed Follow-up). These constraints provide a direct test of whether each of the intervention effects differ in size between immediate post-test and delayed follow-up. Once again imposing these constraints resulted in negligible changes in model fit $\left[\chi^{2}(2)=1.837, p=.399\right]$, confirming that the size of the intervention effects did not differ between the two testing times.
The most critical result from this analysis is that, as expected from the means in Table 2, neither the 20-week nor the 30-week intervention groups show a significantly greater increase in their scores on the early literacy immediate post-test or delayed followup factor (controlling for pretest scores) than the waiting control group $[d=.09(95 \% \mathrm{CI}-0.131$ to $0.317)$ and $d=.13(95 \% \mathrm{CI}-0.125$ to 0.387$)$ respectively]. Once again a model with interactions between group dummy and Literacy Pretest confirmed that a model where slopes are constrained to be equal is valid. In this model, as in the model for language skills, the literacy factor does not show factorial invariance (unstandardized factor loadings vary across testing times).

In addition to word-level reading and letter-sound knowledge, we assessed intervention effects on reading comprehension when it was first administered at delayed follow-up in a hierarchical linear model with children nested within schools (with varying intercepts but fixed slopes across schools). Using baseline listening comprehension skill as the covariate, 


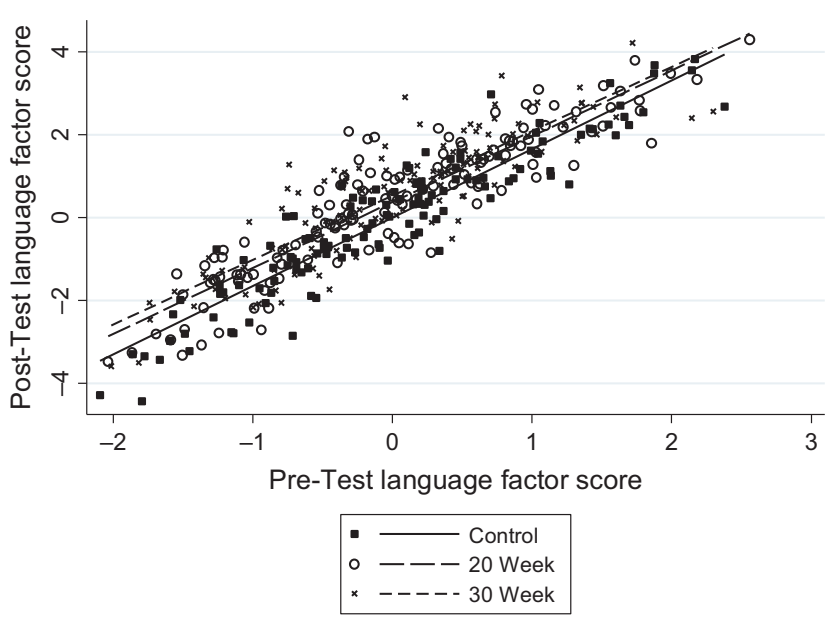

Figure 4 Scatterplot showing the relationship between the outcome variable (post-test language factor score) and the covariate (pretest language factor score) for the 30- and 20-week intervention and the waiting control groups

there was no sign of a difference between the 20week intervention and the waiting control group (marginal mean group difference $=.59,95 \%$ CI -0.29 to $1.49, z=1.30, p=.193$ ) or the 30 -week intervention and the waiting control group (marginal mean group difference $=.37,95 \% \mathrm{CI}-0.54$ to 1.28 ; $z=0.79, p=.427)$.

\section{Discussion}

This study evaluated the effectiveness of the Nuffield Early Language Intervention in a field trial. A key aim was to assess the extent to which the programme is effective when delivered without the extensive support used in our earlier research trial (Fricke et al., 2013). A subsidiary aim was to evaluate whether the original 30-week programme [10 weeks at the end of nursery in England (age 3-4) followed by 20 weeks in first two terms of primary school, that is Reception in England (age 4-5)] differed appreciably from simply delivering a 20 -week programme starting in Reception. The overall pattern of results is clear; both the 20- and 30-week programmes produce small improvements on the standardized tests of oral language skill immediately following the intervention and these effects are maintained 6 months later. Although the size of improvements tended to be larger for the 30-week programme, this difference was not statistically significant. In contrast to the effects on oral language, we did not find evidence that the programmes reliably improved early literacy or reading comprehension skills.

The effects of the 30-week programme on oral language skills is broadly in line with findings from Fricke et al. (2013) although the effects are smaller. The smaller effect sizes likely reflect differences in treatment fidelity (many children in the current study received less than the full 'dose' of the programme) and differences in the quality of training and ongoing support given to the TAs in this study compared to our earlier trial (Fricke et al., 2013). To put the size of these effects in context, according to the method of reporting favoured by the Education Endowment Foundation (2016) the 30-week programme produced gains in language skills equivalent to roughly 4 months additional progress and the 20 -week programme gains of roughly 2 months. For studies of educational interventions at least two

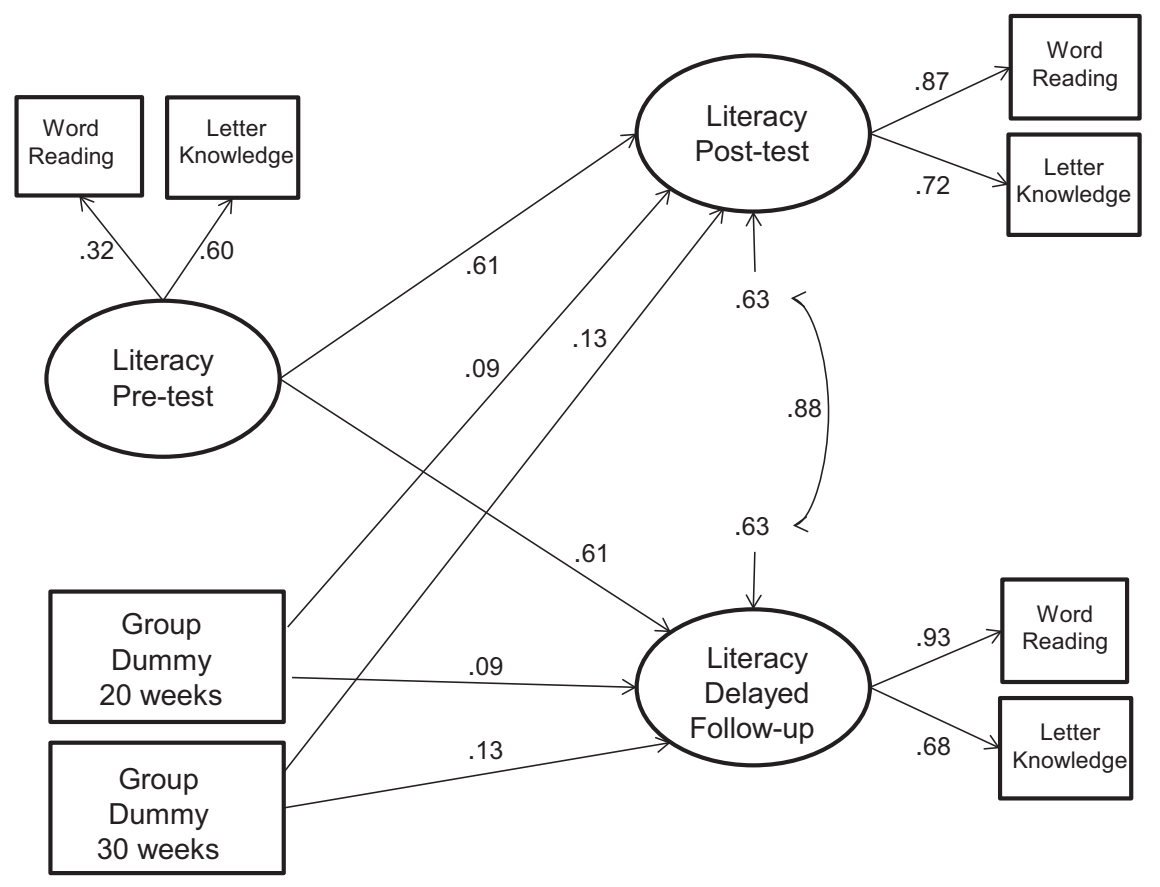

Figure 5 Model showing the effects of the interventions on literacy skills at immediate post-test and delayed follow-up. Standardized coefficients shown (except for dummy variables where y-standardized values are shown). Robust (Huber-White cluster estimators) standard errors are shown which do not differ appreciably from simple standard errors. Some covariances between the same measures at adjacent time points were significant and included in the model, but not shown in the diagram 
organizations (Promising Practices Network, 2007; What Works Clearing House, 2007) have suggested that $d=.25$ should be seen as educationally important although it is also worth noting that smaller effect sizes can in certain circumstances be considered to have high practical importance (Cooper, 2008).

It is encouraging that the intervention effects are maintained at delayed follow-up, by which time some of the children in the waiting control group were receiving some form of intervention, albeit of highly variable quality and quantity. It is hard to know why some schools preferred not to be trained in the additional language and literacy support that we offered for the waiting control group, or why some who accepted the training delayed its implementation. However, it is encouraging to note that, immediately following the trial, 10 schools continued to use the Nuffield Early Language Intervention in nursery and/or Reception and a further 9 schools intended to use it again.

We found no statistically significant difference between the 30-week and 20-week programmes. The preschool component of the programme, however, was of limited duration (10 hr) and consisted only of group work with no individual sessions. Further work is needed to establish the best form of language intervention for children in nursery.

The absence of intervention effects on early literacy skills replicates Fricke et al. (2013). This likely reflects the fact that all children were receiving intensive systematic phonics teaching in their schools. In addition, although Fricke et al. (2013) found significant improvements in reading comprehension some 6 months after the end of the intervention, this was not the case in the current study, most likely because the improvements in language skills here are much smaller than those in the earlier study.

\section{Conclusion}

Oral language skills are critical to educational success (Roulstone et al., 2011) and this study provides evidence that the benefits of the Nuffield Early Language Intervention (Fricke et al., 2013) are reproducible when training is delivered by an independent organization, in 'real world' educational settings (cf. Savage, Carless, \& Erten, 2009). Further research is needed to evaluate whether a more intensive nursery-based language intervention programme would be effective in boosting the language skills of preschool children (we suspect it would). It would also be desirable for future studies to assess the longer term effects of early language interventions and their potential cost effectiveness.

\section{Supporting information}

Additional Supporting Information may be found in the online version of this article:

Appendix S1. Group and individual session schedule. Appendix S2. CONSORT checklist (Schulz et al., 2010).

\section{Acknowledgements}

The research was funded by a grant from the Education Endowment Foundation (EEF). Funding for the development of the Nuffield Early Language Intervention programme was provided by the Nuffield Foundation. We thank many colleagues for their assistance with data collection, and the teaching assistants, schools, children and parents for their participation. Revenue from sales of the Nuffield Early Language Intervention programme are used for charitable purposes. The authors declare no competing or potential conflicts of interests.

\section{Correspondence}

Silke Fricke, Department of Human Communication Sciences, University of Sheffield, 362 Mushroom Lane, Sheffield S10 2TS, UK; Email: S.Fricke@sheffield.ac.uk

\section{Key points}

- Oral language skills are critical to educational success.

- Data from a randomized controlled trial show that both a 30-week language intervention delivered in nursery and Reception classes in England and a 20-week intervention delivered in Reception only can improve oral language skills.

- The intervention did not bring about reliable gains in early literacy or reading comprehension skills.

- The findings provide further evidence that oral language interventions can be delivered successfully by teaching assistants working in schools.

\section{References}

Altman, D.G., \& Bland, J.M. (2005). Treatment allocation by minimization. British Medical Journal, 330, 843

Beck, I., \& McKeown, M.G. (2007). Increasing young low-income children's oral vocabulary repertoires through rich and focused instruction. The Elementary School Journal, 107, 251-271.
Beck, I.L., McKeown, M.G., \& Kucan, L. (2013). Bringing words to life: Robust vocabulary instruction. New York: Guilford Press.

Bianco, M., Bressoux, P., Doyen, A.L., Lambert, E., Lima, L., Pellenq, C., \& Zorman, M. (2010). Early training in oral comprehension and phonological skills: Results of a threeyear longitudinal study. Scientific Studies of Reading, 14, 211-246. 
Bowyer-Crane, C., Snowling, M.J., Duff, F.J., Fieldsend, E., Carroll, J.M., Miles, J., .. . \& Hulme, C. (2008). Improving early language and literacy skills: Differential effects of an oral language versus a phonology with reading intervention. Journal of Child Psychology and Psychiatry, 49, 422-432.

Boyle, J., McCartney, E., O’Hare, A., \& Law, J. (2010). Intervention for mixed receptive-expressive language impairment: A review. Developmental Medicine and Child Neurology, 52, 994-999.

Carroll, J.M., Bowyer-Crane, C., Duff, F.J., Hulme, C.J., \& Snowling, M.J. (2011). Developing Language and Literacy: Effective Intervention in the Early Years. Oxford: WileyBlackwell.

Cirrin, F.M., \& Gillam, R.B. (2008). Language intervention practices for school-age children with spoken language disorders: A systematic review. Language, Speech, and Hearing Services in Schools, 39, S110-S137.

Clarke, P.J., Snowling, M.J., Truelove, E., \& Hulme, C. (2010). Ameliorating children's reading comprehension difficulties: A randomized controlled trial. Psychological Science, 21, 1106-1116.

Conti-Ramsden, G., Durkin, K., Simkin, Z., \& Knox, E. (2009). Specific language impairment and school outcomes. I: Identifying and explaining variability at the end of compulsory education. International Journal of Language and Communication Disorders, 44, 15-35.

Cooper, H. (2008). The search for meaningful ways to express the effects of interventions. Child Development Perspectives, 2, 181-186.

DCSF (2008). Statutory framework for the early years foundation stage. Nottingham, UK: Author.

DfES (2006). Primary framework for literacy and mathematics. Norwich, UK: Author.

DfES (2007). Letters and Sounds: Principles and practice of high quality phonics. Norwich: Author.

Dunn, L.M., Dunn, D.M., \& Styles, B. (2009). British Picture Vocabulary Scale (3rd edn). London: GL Assessment.

Education Endowment Foundation (2016). Nuffield early language intervention: Evaluation report and executive summary. Available from: https://educationendowmentf oundation.org.uk/our-work/projects / nuffield-early-langua ge-intervention [last accessed 13 February 2017].

Elleman, A.M., Lindo, E.J., Morphy, P., \& Compton, D.L. (2009). The impact of vocabulary instruction on passage-level comprehension of school-age children: A meta-analysis. Journal of Research on Educational Effectiveness, 2, 1-44.

Fricke, S., Bowyer-Crane, C., Haley, A., Hulme, C., \& Snowling, M. (2013). Efficacy of language intervention in the early years. Journal of Child Psychology and Psychiatry, 53, 280290.

Hulme, C., Nash, H., Gooch, D., Lervåg, A., \& Snowling, M. (2015). The foundations of literacy development in children at familial risk of dyslexia. Psychological Science, Epub ahead of print. https:/ /doi.org/10.1177/0956797615603702.

Hulme, C., Stothard, S.E., Clarke, P., Bowyer-Crane, C., Harrington, A., Truelove, E., \& Snowling, M.J. (2009). York Assessment of Reading for Comprehension: Early reading. London: GL Assessment.

Ioannidis, J.P. (2006). Evolution and translation of research findings: From bench to where. PLoS Clinical Trials, 1, e36.
Law, J., Garrett, Z., \& Nye, C. (2004). The efficacy of treatment for children with developmental speech and language delay/ disorder a meta-analysis. Journal of Speech, Language, and Hearing Research, 47, 924-943.

Law, J., Roulstone, S., \& Lindsay, G. (2015). Integrating external evidence of intervention effectiveness with both practice and the parent perspective: Development of 'What Works' for speech, language, and communication needs. Developmental Medicine and Child Neurology, 57, 223-228.

Locke, A. (2006). One Step at a Time. London: Network Continuum Education.

Lonigan, C.J., Shanahan, T., \& Cunningham, A. (2008). Impact of shared-reading interventions on young children's early literacy skills. In Developing early literacy: Report of the National Early Literacy Panel (pp. 153-171). Washington, DC: National Institute for Literacy.

Mol, S.E., Bus, A.G., de Jong, M.T., \& Smeets, D.J. (2008). Added value of dialogic parent-child book readings: A metaanalysis. Early Education and Development, 19, 7-26.

Muthén, L.K., \& Muthén, B.O. (1998-2015). Mplus 7.4. Los Angeles: Muthén \& Muthén.

Neuman, S.B., Newman, E.H., \& Dwyer, J. (2011). Educational effects of a vocabulary intervention on preschoolers' word knowledge and conceptual development: A cluster-randomized trial. Reading Research Quarterly, 46, 249-272.

NICHD Early Child Care Research Network (2005). Pathways to reading: The role of oral language in the transition to reading. Developmental Psychology, 41, 428-442.

Promising Practices Network (2007). How programs are considered. Available from: http://www.promisingpractices.ne t/criteria.asp [last accessed 25 March 2007].

Renfrew, C. (2003). Action picture test. Milton Keynes: Speechmark.

Roulstone, S., Law, J., Rush, R., Clegg, J., \& Peters, T. (2011). Investigating the role of language in children's early educational outcomes (Project Report). Bristol, UK: DfE.

Savage, R., Carless, S.U.E., \& Erten, O. (2009). The longerterm effects of reading interventions delivered by experienced teaching assistants. Support for Learning, 24, 95-100.

Schulz, K.F., Altman, D.G., \& Moher, D. (2010). Consort 2010 statement: Updated guidelines for reporting parallel group randomised trials. British Medical Journal, 340, c332. https://doi.org/10.1136/bmj.c332.

Semel, E., Wiig, E., \& Secord, W. (2006). Clinical evaluation of language fundamentals-Preschool UK (2nd edn). Oxford: Pearson Assessment.

Snowling, M., Adams, J., Bishop, D.V.M., \& Stothard, S. (2001). Educational attainments of school leavers with a preschool history of speech-language impairments. International Journal of Language and Communication Disorders, 36, 173-183.

Snowling, M., Stothard, S., Clarke, P., Bowyer-Crane, C., Harrington, A., Truelove, E., ... \& Hulme, C. (2009). YARC York assessment of reading for comprehension: Passage reading. London: GL Assessment.

What Works Clearing House (2007). Review process: Standards. Available from: http://www.whatworks.ed.gov/revie wprocess/standards.html [last accessed 26 February 2007].

Accepted for publication: 9 March 2017

First published online: 19 May 2017 